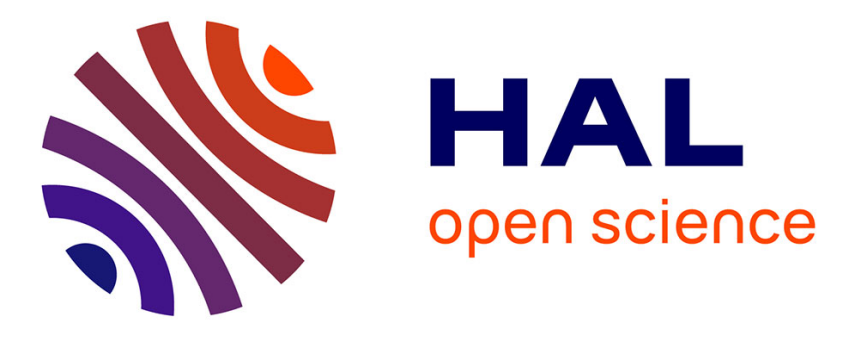

\title{
Detectability and annoyance of warning sounds for electric vehicles
}

\author{
Etienne Parizet, Ryan Robart, Jean-Christophe Chamard, Joseph \\ Schlittenlacher, Perceval Pondrom, Wolfgang Ellermeier, Fabio Biancardi, \\ Karl Janssens, Paul Speed-Andrews, James Cockram, et al.
}

\section{To cite this version:}

Etienne Parizet, Ryan Robart, Jean-Christophe Chamard, Joseph Schlittenlacher, Perceval Pondrom, et al.. Detectability and annoyance of warning sounds for electric vehicles. International Congress on Acoustics 2013, 2013, Montréal, Canada. pp.2aNSa5. hal-00994690

\section{HAL Id: hal-00994690 \\ https://hal.science/hal-00994690}

Submitted on 21 May 2014

HAL is a multi-disciplinary open access archive for the deposit and dissemination of scientific research documents, whether they are published or not. The documents may come from teaching and research institutions in France or abroad, or from public or private research centers.
L'archive ouverte pluridisciplinaire HAL, est destinée au dépôt et à la diffusion de documents scientifiques de niveau recherche, publiés ou non, émanant des établissements d'enseignement et de recherche français ou étrangers, des laboratoires publics ou privés. 


\title{
Proceedings of Meetings on Acoustics
}
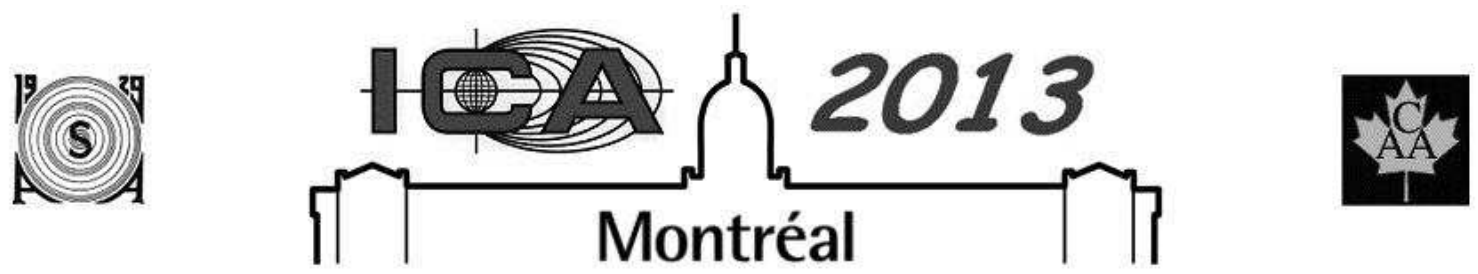

\author{
ICA 2013 Montreal \\ Montreal, Canada
}

2 - 7 June 2013

Noise

Session 2aNSa: Transportation Noise

\section{2aNSa5. Detectability and annoyance of warning sounds for electric vehicles}

Etienne Parizet*, Ryan Robart, Jean-Christophe Chamard, Joseph Schlittenlacher, Perceval Pondrom, Wolfgang Ellermeier, Fabio Biancardi, Karl Janssens, Paul Speed-Andrews, James Cockram and Gemma Hatton

*Corresponding author's address: LVA INSA-Lyon, Villeurbanne, F-69621, Rhône, France, etienne.parizet@insa-lyon.fr

Electric or hybrid vehicles are very quiet at low speeds, which represents a very good opportunity to reduce traffic noise annoyance in cities. On the other hand, this may be very hazardous for vulnerable pedestrians (e.g. visually impaired people). The aim of the eVADER project is to propose solutions in order to add warning sounds to such cars, while fulfilling two contradictory goals : sounds should be detectable but should not contribute to traffic noise annoyance. Different perceptual experiments have been conducted : the first one evaluated the influence of various timbre parameters on sound detectability. It was shown that an electric vehicle equipped with one particular sound was as easily detected as a diesel one, while keeping a very low level. Then the influence of some timbre parameters (pitch and temporal modulation frequency) on the distance and speed as perceived by listeners was measured. Finally, a third experiment was devoted to the consequence on traffic noise annoyance of such warning sounds.

Published by the Acoustical Society of America through the American Institute of Physics 


\section{INTRODUCTION}

Electric vehicles are very quiet, especially for speeds lower than $40 \mathrm{~km} / \mathrm{h}$. The difference in noise level e between these quiet vehicles and an average conventional one is about $8 \mathrm{~dB}(\mathrm{~A})$, as measured according to the regulation for exterior car noise [1]. This is especially dangerous for visually-impaired people, as they have to rely on auditory cues when intending to cross a road $[2,3]$. Therefore, car manufacturers use loudspeakers mounted on such quiet vehicles to warn pedestrians that the car is approaching.

The eVADER project (Electric Vehicle Alert for Detection and Emergency Response) is funded by the European Commission and aims to provide an optimal design of such warning sounds. This means that these sounds should satisfy three requirements :

- $\quad$ they should be easily detected by the pedestrian, in spite of the background noise. During the next decade, it is expected that this background noise will be mainly due to conventional vehicles;

- $\quad$ they should give some useful information to visually-impaired people about the speed of the car.

- But they should not be too loud, as a major advantage of electric and hybrid vehicles is that they can dramatically reduce traffic noise level in cities.

Partners of this project are car manufactures, suppliers, universities and the European Blind Union, which is a non-governmental and non-profit organization representing the interests of non-sighted people in Europe.

Three listening tests were proposed in this project. The first one aims at evaluating the influence of several timbre parameters on warning sound detection. The goal of the second experiment was to test if certain sound features are differentially informative to visually-impaired listeners with regard to vehicle dynamics, such as speed. The third experiment will be devoted to the noise annoyance of such sounds, as felt by other pedestrians.

At the time this paper was prepared, only the first experiment was completed. This paper will present its results. Results of the second experiment will be presented during the congress.

\section{EXPERIMENTAL PROCEDURE}

The goal of this experiment was to evaluate the detectability of several warning sounds. A common situation was considered : a pedestrian standing on sidewalk, facing perpendiculat to the street while waiting to cross it. An electric vehicle and a diesel one were recorded while passing close to a dummy head in that situation, from 30 meters to the right of the dummy head to 30 meters to its left (or vice-versa). The speed of the cars was $20 \mathrm{~km} / \mathrm{h}$. Then various warning sounds were mixed with the recordings of the electric car.

The warning sound stimuli were designed to satisfy the previously mentioned requirements and to investigate three parameters of timbre : tonal content, frequency detuning and amplitude modulation. For each factor, three levels were considered.

Tonal content represents the number of harmonics within the sound. There were three levels of tonal content: 3 , 6 or 9 harmonic complexes. In all cases, the tones used were sinusoidal, and the lowest frequency of the sound was $300 \mathrm{~Hz}$, due to expected technical reasons of the loudspeakers.

The second factor of frequency detuning had three levels as well. Frequency detuning could be null (purely harmonic). At a second level, a sinusoidal frequency modulation was applied to the two highest harmonics, with two different modulation frequencies $(4$ and $5 \mathrm{~Hz}$ ). The third level represents a saw-tooth modulation applied to these two harmonics. These modulations periodically detuned these harmonics + or $-75 \mathrm{~Hz}$ around these highest harmonics within any given sound.

The third factor studied was amplitude modulation. As in the other factors, the first level of the amplitude modulation factor contained no amplitude modulation (the amplitude of the sound did not vary during time). Sounds containing the level 2 amplitude modulation were sinusoidally modulated $(8 \mathrm{~Hz})$. At the third level, a complex modulation amplitude was applied to all components, which made the sound irregular.

A Taguchi fractional design was applied, which gave 9 combinations of factors (instead of 27 in the case of a complete design). Once the sounds were synthesized, they were modified by a partner of the project (LMS International) so as to simulate a moving source, using a set of head-related transfer functions. Finally they were 
added to the recordings of the electric vehicle. The two original cars (electric one without any warning sound and diesel one) were added in the set of stimuli as two anchors.

Adding warning sounds only slightly increased the peak level of the electric car, as shown in figure 1. The maximum increase is $2 \mathrm{~dB}(\mathrm{~A})$ and the level of the sound of the diesel car is more than $5 \mathrm{~dB}(\mathrm{~A})$ higher than all other sounds.

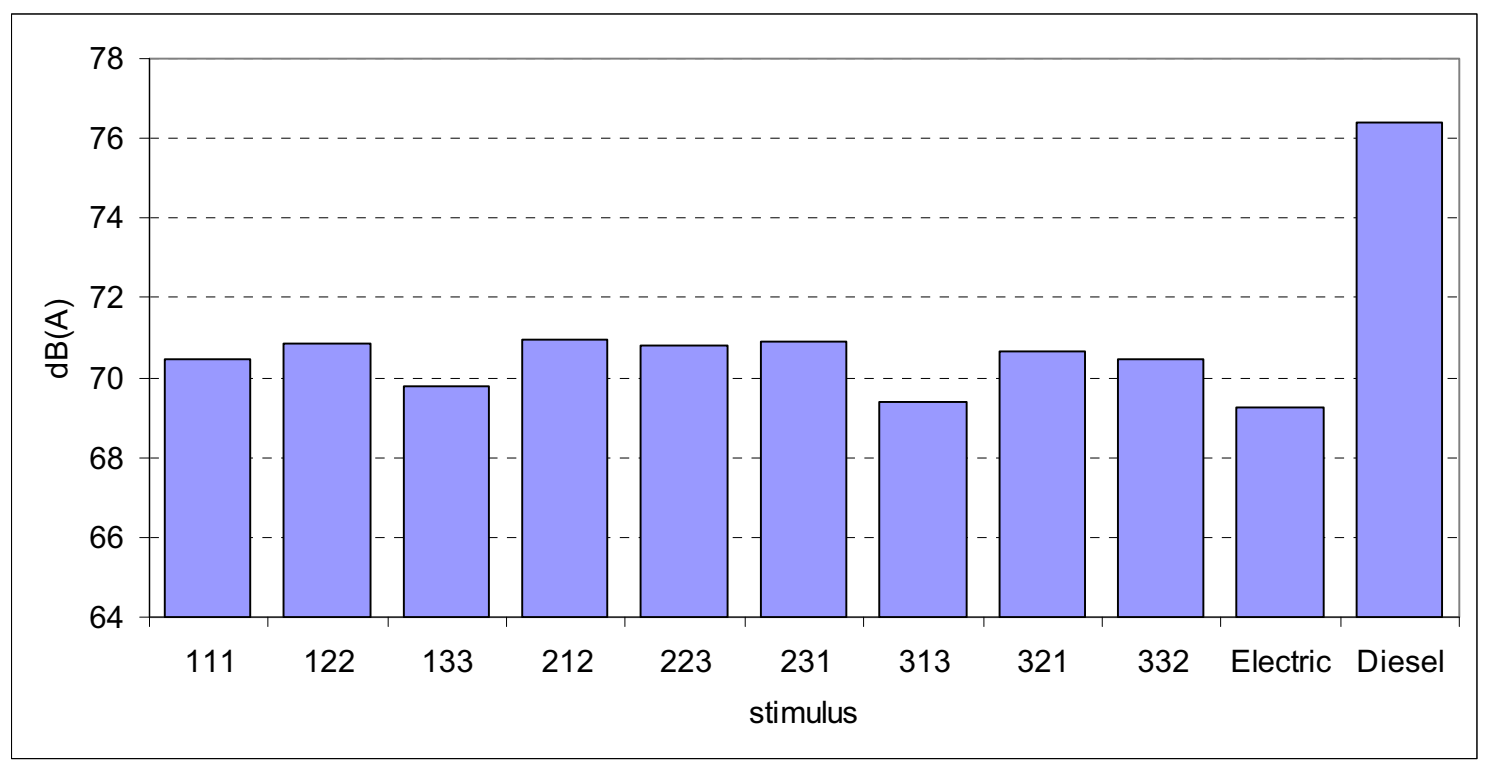

FIGURE 1. Peak level of the 11 stimuli used in the experiment. "111", "122", and so on, refer to the combination of factor levels.

Eight repetitions of each sound (4 from each direction) were randomly presented to the listeners (using electrostatic Stax headphones). This gave a total number of 88 trials. The inter-trial interval was randomly selected between 1 and 20 seconds To make the presentation more realistic. Sounds were presented in a background noise representing a steady flow of traffic. Some rain sounds were added to this background noise as this represents a very difficult situation for visually impaired people walking in the street. The level of this background noise was 69 $\mathrm{dB}(\mathrm{A})$. Sound presentation was managed by a program developed in Delphi, running on a computer outside of the booth in which the listener was seated.

The task of the listeners was to detect the arrival of each car. They had to press the space bar of the computer keyboard as soon as possible if they thought the car arrived from the left, and the return key if they thought the car arrived from the right.. Detection was measured by reaction time, and localization errors were recorded.

The experiment was conducted in three different labs (INSA-Lyon, PSA and NISSAN). All together, 91 listeners (aged 20 to 72) participated to the experiment. Among them, 33 were visually impaired.

\section{RESULTS}

Data from 7 participants were rejected as they showed many misses or side errors (for more than $40 \%$ of the stimuli). It appeared that the average response time could be quite different between subjects, as can be seen in figure 2. In this figure, response times have been converted to distances to the car at detection. 


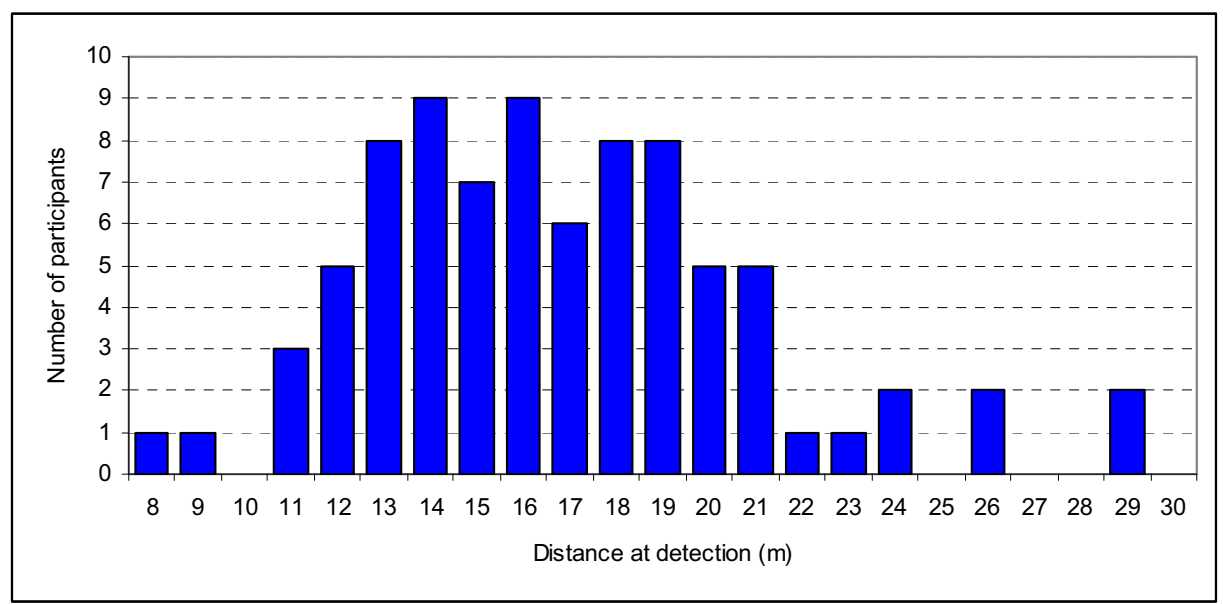

FIGURE 2. Average distance at which the car sounds were detected - pooled across sounds per individual listener.

Some participants could detect the car nearly as soon as it appeared (when the car was still 29 meters away) while others made their response when the car was very close to them (less thant 10 meters). No relation could be found between this averaged response time and some participants characteristic (e.g. gender or age). Also, it was expected that visually impaired people would have lower detection latencies than sighted ones, but this was not true.

This individual mean response time was substracted from all raw data of the corresponding participant. As a result, the inter-individual variability per experimental condition became quite small. Figure 3 shows the thus normalized distance measure as a function of the warning signal added to the vehicle sound and the two control conditions (electric or diesel engines without additional warning).

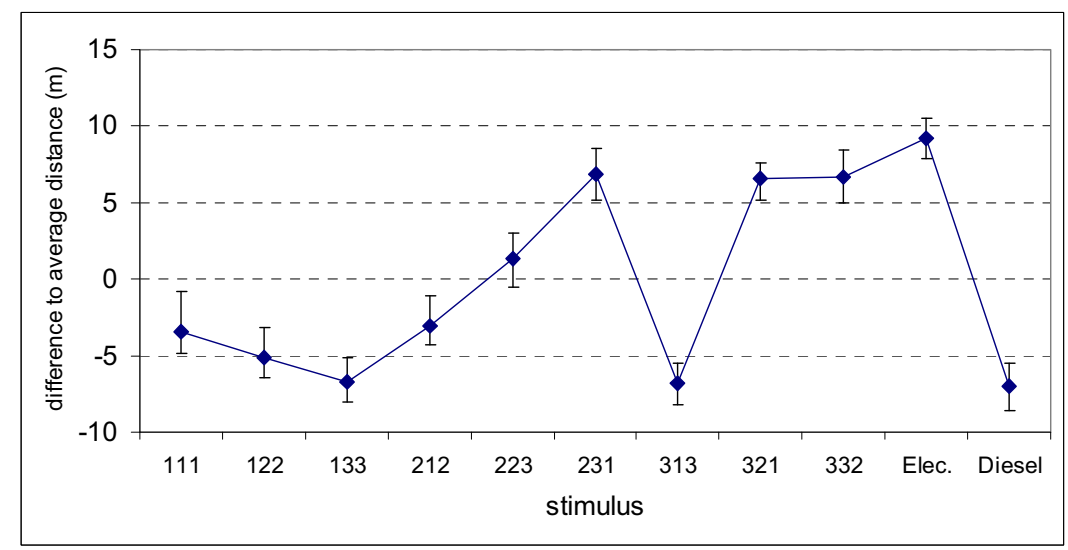

FIGURE 3. Difference to the mean distance at detection of each vehicle-warning combination (median and interquartile range).

It can be seen that the electric vehicle (without any warning sound) was 16 meters closer to the pedestrian than the diesel car when these two vehicles were detected. This confirms that electric vehicles can be dangerous at low speed.

The main result is that some warning sounds (e.g. 133 or 313) can facilitate the detection of the electric car so that it is as easily detected as the diesel car. On the other hand, some other warning sounds $(231,321$ and 322$)$ do not improve performance with respect to the situation without warning. Figure 1 shows that such differences cannot be explained by level differences of the sounds. It appears that the temporal irregularity of warning sounds is a key factor. 


\section{CONCLUSION}

This study showed that carefully selected warning sounds can facilitate the detection of electric vehicles without being too loud. A second experiment will focus on the information that a warning sound can give to the pedestrian about the speed of the approaching car. Its results will be presented during the conference.

\section{ACKNOWLEDGMENTS}

This study was funded by the European Commission (ref. SCP1-GA-2011-285095).

\section{REFERENCES}

1. F. Dubois, G. Baudet and J.C. Chamard, "EVADER : Electric Vehicle Alert for Detection and Emergency Response", Proc. Acoustics 2012, $12^{\text {th }}$ Congress of the French Acoustical Association.

2. National Highway Traffic Safety Administration, "Quieter Cars and the safety of blind pedestrians: phase 1", DOT HS 811 304, April 2010.

3. National Highway Traffic Safety Administration, "Incidence of Pedestrian and Bicyclist Crashes by Hybrid Electric Passenger Vehicles", DOT HS 811 204, Sept. 2009.

4. G. Taguchi, S. Knishi, "Taguchi methods. Orthogonal arrays and linear graphs. Tools for quality engineering", American Supplier Institute Press, Dearborn (1987).

5. V. Koehl, E. Parizet, "'Influence of strutural variability upon sound perception : usefulness of fractional factorial designs", Applied Acoustics 67 (2006), 249-270. 